\title{
THE EVOLUTION OF VERBAL BEHAVIOR
}

\section{B. F. SKINNER}

\section{HARVARD UNIVERSITY}

Evolutionary theory has always been plagued by scantiness of evidence. We see the products of evolution but not much of the process. Most of the story happened long ago, and little remains of the early stages. Especially few traces of behavior remain; only recently were there artifacts that could endure. Verbal behavior left no artifacts until the appearance of writing, and that was a very late stage. We shall probably never know precisely what happened, but we ought to be able to say what might have happened - that is, what kinds of variations and what kinds of contingencies of selection could have brought verbal behavior into existence. Speculation about natural selection is supported by current research on genetics; the evolution of a social environment or culture is supported by the experimental analysis of behavior.

Strictly speaking, verbal behavior does not evolve. It is the product of a verbal environment or what linguists call a language, and it is the verbal environment that evolves. Since a verbal environment is composed of listeners, it is understandable that linguists emphasize the listener. (A question often asked, for example, is, "How is it possible for a person to understand a potentially infinite number of sentences?" In contrast, a behavioral analysis asks, "How is it possible for a person to say a potentially infinite number of sentences?") This paper, then, is about the evolution of a verbal environment as the source of the behavior of the speaker.

The plausibility of a reconstruction depends in part upon the size of the variations that are assumed to have occurred; the smaller the variations, the more plausible the explanation. Web-making in the spider, for example, could scarcely have appeared all at once in its present form as a variation. More plausible is a series of small steps. The excretion that eventually became silk may have begun

Requests for reprints may be sent to the author at Department of Psychology, William James Hall, Harvard University, Cambridge, Massachusetts 02138. as a coating for eggs. It worked better when it took the form of fibers with which eggs could be wrapped rather than coated. The fibers helped the spiders keep from falling as they worked and did so more effectively as they grew stronger. The spiders might have begun to lift and lower themselves with the fibers, and strands that were left behind might have caught insects, which the spiders ate. The more strands left, the more insects caught. Some patterns of strands caught more than others. And so on. That may not be exactly what happened, but it is easier to believe than the appearance of web-making as a sudden, single variation. The evolution of behavior is also more plausibly regarded as the product of a series of small variations and selections. It is rather like the shaping of operant behavior through small changes in contingencies of reinforcement, and what we have learned about the operant process helps in understanding the genetic in spite of the great differences between them.

\section{PHYLOGENIC "SIGNALING"}

The word "sign" does not commit its user to any theory of language. Smoke is a sign of fire and dark clouds a sign of rain. The growl of a vicious dog is a sign of danger. Organisms come to respond to signs through well known behavioral processes. To "signal" is to make a sign; we account for it through the selecting consequences that would have followed. Fire and rain do not signal, but dogs do, if what other animals have done when they have growled has played a part in the selection of growling. There are difficulties in explaining the evolution of even that relatively simple example, however, and other kinds of "signaling" raise other problems.

Organisms must have profited from the behavior of each other at a very early stage through imitation. To imitate is more than to do what another organism is doing. Pigeons foraging in a park are not imitating each other 
to any great extent; they are acting independently under similar environmental contingencies. To imitate is to act as another organism is acting because important consequences have then followed. The evolution of the process can be traced to plausible selective consequences: The contingencies responsible for the imitated behavior may affect another organism when it behaves in the same way. Thus, if one of two grazing animals sees a predator and runs, the other is more likely to escape if it runs too, although it has not seen the predator. Running whenever another organism runs usually has survival value.

It was only after a tendency to imitate had evolved that contingencies existed for the evolution of the reciprocal process of modeling. A young bird that would eventually learn to fly without help learns sooner when it imitates a flying bird. Its parents can speed the process by flying where the young bird can see them and in ways that are easily imitated. To say that the parents are "showing their young how to fly" adds nothing to such an account and may imply more than is actually involved.

The evolution of other kinds of reciprocally helpful behavior is not so easily explained. For example, what would have been the survival value of the dance of the honeybee returning from good forage before other bees responded to the dance, and how could responding to it have evolved before bees danced? (The question is not raised by imitation and modeling because the contingencies that account for imitation do not require modeling.) We must assume that the distance or the direction in which the returning bees traveled had some other effect upon their behavior. Perhaps signs of fatigue varied with the distance, or phototropic movements varied according to the position of the sun on their return. Once reciprocal behavior had evolved, further variations could make it more effective. Returning bees could dance in more conspicuous ways and other bees could respond more accurately to features of the dance. It is often said that bees have a language, that they "tell each other where good forage is to be found," that the dance "conveys information," and so on. Such expressions, useful enough in casual discourse, add nothing to an explanation in terms of natural selection and may obscure the processes at issue.

\section{ONTOGENIC "SIGNALING”}

Contingencies of reinforcement resemble contingencies of survival in many ways. Animals learn to imitate when, by doing what others are doing, they are affected by the same contingencies - of reinforcement rather than of survival. Once that has happened, contingencies exist in which others learn to modelto behave in ways that can be more easily imitated. If, for example, a door can be opened only by sliding it to one side, rather than pushing or pulling it, a person slides it when he sees another person do so, although the other person is not necessarily modeling the behavior. In such an example, both parties may exhibit traces of phylogenic imitation or modeling, but the operant contingencies would suffice. If the modeler is not close to the door, he can make the kind of movement that would open it if he were-as a gesture. To say that he is "showing the other how to open the door" is useful in casual discourse but, again, potentially troublesome in a scientific account.

When a gesture is not a kind of modeling, we must ask what could have reinforced it before anyone responded appropriately, and how anyone could have learned to respond before it had come into existence as a gesture. How, for example, could the gesture with which a traffic officer stops an approaching car have been acquired before people stopped in response to it, and how could people have learned to stop before anyone gestured that way? As in the case of the bees, other contingencies related to stopping are needed and, of course, are not hard to find. One person can stop another by placing a hand on his chest, and if the person who is stopped finds the contact aversive, he will stop on later occasions before contact is made. The movement of arm and hand changes from a practical response to a gesture. Once that has happened, the topography can change until it would have little or no physical effect.

The gesture that means "Come here" is another example. It presumably originated as practical pulling but became effective as a gesture when people who were pulled moved quickly to avoid physical contact. The topography of the gesture still varies with distance, possibly because of its visibility, but also as if some practical work remained to be done: When the parties are far apart, the whole arm 
is moved; when they are fairly near, only the forearm; and when they are close, only the hand or just a finger.

\section{VOCAL BEHAVIOR}

The human species took a crucial step forward when its vocal musculature came under operant control in the production of speech sounds. Indeed, it is possible that all the distinctive achievements of the species can be traced to that one genetic change. Other species behave vocally, of course, and the behavior is sometimes modified slightly during the lifetime of the individual (as in birdsong, for example), but there the principal contingencies of selection have remained phylogenic-either physical (as in echo location) or social. Parrots and a few other birds imitate human speech, but it is hard to change the behavior or bring it under stimulus control through operant conditioning.

Some of the organs involved in the production of speech sounds were already subject to operant conditioning. The diaphragm must have participated in controlled breathing, the tongue and jaw in chewing and swallowing, the jaw and teeth in biting and tearing, and the lips in sipping and sucking, all of which could be changed through operant conditioning. Only the vocal cords and pharynx seem to have served no prior operant function. They presumably evolved as organs for the production of phylogenic calls and cries. The crucial step in the evolution of verbal behavior appears, then, to have been the genetic change that brought them under the control of operant conditioning and made possible the coordination of all these systems in the production of speech sounds. Since other primates have not taken that step, the change in man was presumably recent. The possibility that it may not yet be complete in all members of the species may explain why there are so many speech disorders - and perhaps even so many individual differences in complex verbal behavior, such as mathematics.

Vocal behavior must have had several advantages in natural selection. Sounds are effective in the dark, around corners, and when listeners are not looking, and they can be made when the hands are busy with other things. There are special advantages, however, in large operant repertoires, especially the enor- mous variety of available speech sounds. Gestures are not as conspicuously different as speech sounds and hence are fewer in number, and the sounds one produces are more like the sounds one hears than gestures are like the gestures one sees (because they are seen from a different point of view). One learns to gesture through movement duplication but to speak through product duplication, which is more precise.

It is easier to account for the evolution of operant conditioning if we assume that the first contingencies of reinforcement closely resembled contingencies of natural selection, since only small variations are needed if the settings, topographies, and consequences are similar (see Skinner, 1984). That could have been true of vocal operants. The cry of a hungry baby, for example, presumably evolved as phylogenic behavior because it alerted the baby's parents, but when, through an evolutionary change, the attention of the parents could begin to act as a reinforcer, crying would become an operant, with added advantages for baby and species. Once in existence as an operant, however, crying could appear in circumstances too unstable to figure in natural selection. A baby that was not hungry, for example, could cry in a manner from which the parents would escape by doing things that had no necessary advantage for the species.

A similarity of phylogenic or ontogenic contingencies is not, of course, needed. Coughing, for example, presumably evolved as a reflex that cleared the throat of irritants, but as soon as the vocal musculature came under operant control, it could be affected by a different consequence, such as the attention of a listener. If listeners continued to respond, the topography could change until it had no effect on the throat. The cough would become the verbal operant "Ahem!" That could have happened before the vocal cords came under operant control, and something like it may have been the first move from gesture to vocal, but not voiced, behavior.

Although early vocal operants could have been "primed" in this way by phylogenic behavior, the evolution of operant conditioning appears to have been accompanied by the evolution of a pool of behavior that played no other part in natural selection and was therefore more readily subject to operant reinforce- 
ment (see Skinner, 1984). An obvious vocal example is the babbling of small childrenessentially random sounds that, when picked up by reinforcers, became operants. Verbal behavior drawn from a pool of uncommitted behavior has no connection with phylogenic calls or cries, and in general we have no reason to call it an extension of vocal phylogenic "signaling."

\section{A Vocal Episode}

Let us say that two men, $A$ and $B$, are fishing together. A shallow net containing bait is lowered into the water, and when a fish swims into the net, it is quickly pulled up. Let us say that $A$ lowers and raises the net and $B$ takes a position from which he can more clearly see it. Anything $B$ does when a fish enters the net will serve as a discriminative stimulus for $A$, in the presence of which pulling will more often be reinforced by the appearance of a fish in the net. $B$ can model pulling, if he has already learned to model, but nothing more is needed than what we might call a sign of "excitement" at the presence of a fish in the net or of "annoyance" at $A$ 's failure to pull. Whatever the behavior, it begins to function as a gesture as soon as it has been reinforced by $A$ 's response (and, presumably, by a share of the fish). The behavior patterns of both parties then slowly change as their roles become more sharply defined. $B$ becomes more clearly the observer, moving into the best position to see the fish and gesturing as quickly and as effectively as possible, and $A$ becomes more clearly the actor, watching $B$ more closely and pulling as quickly as possible when $B$ responds.

Let us say that, as $A$ and $B$ continue to fish cooperatively, a vocal response (perhaps the undifferentiated $U h$, requiring no operant control of the vocal cords) is selected by its convenience for $B$ and by the speed and consistency with which it reaches $A$. We could then describe the episode in either of two ways. In traditional terms, we could say that "When $B$ says $U h$, he is telling $A$ that there is a fish in the net" and that he uses $U h$ as a word that "means fish or refers to a fish." Or we could say that $B$ is "telling $A$ to pull the net," in which case $U h$ means "pull."

Cooperative fishing suggests sharing the fish, but the roles are clearer if one party gets the fish and induces the other to behave by other means. If $B$ gets the fish and arranges reinforcing consequences for $A, U h$ would be classified in several different ways according to the kind of consequence arranged. If $A$ pulls because in the past $B$ has punished his not having pulled, $U h$ is a command. If $B$ has paid $A$, it is an order. If the two are friends, disposed to help each other, it is a request. On the other hand, if $A$ gets the fish and somehow reinforces $B$ 's response, $U h$ would be called a "report" or an "announcement" of the presence of a fish in the net. But although these traditional expressions may be useful in casual discourse, they do not take us very far toward a scientific account. The episode is nothing more than an instance of the reciprocal behavior of two people, and the contingencies that account for it are clear.

\section{Tacts and Mands}

Something more is needed if we are to call $U h$ either a mand or a tact: The consequences must be generalized. The necessary generalization presumably came about when there were many cooperative activities in which a single object (such as a fish) or a single action (such as pulling) played a part. Fish are picked up, carried, put down, cleaned, cooked, eaten, and so on. Although things sometimes have, as we say, "different names according to what is done with them," a single form should emerge through stimulus generalization. A tact emerges as the probability of saying fish in the presence of a fish when different instances are followed by different reinforcing consequences, quite apart from any other feature of a particular setting. Perhaps there is then no particular harm in using traditional words and saying that fish "refers to a fish" or "means fish," where the meaning or referent is simply the fish as the principal controlling variable. To say that the speaker uses the word to mean fish or to refer to a fish is, however, to get ahead of our story.

As a mere probability of responding, the nature of a tact is clearer when we would not speak of meaning or reference. Let us say that we are calling on someone who has a large sailfish mounted on the wall of his office. We start looking for something in our briefcase and, when asked what we are doing, say, "I am fishing for a letter I want to show you." The fish on the wall has strengthened fish as a tact and has entered into the choice of a synonym. (If, instead, there had been a display of guns on the wall, we might have been more likely to say, "I am hunting for a letter.") In such a case we do not say that "fish- 
ing" refers to the fish on the wall, even though it has been strengthened by it.

As a mere probability of responding, a tact has the same status as three types of verbal operants that are also not said to mean or refer to their controlling variables. One is echoic (we should have been more likely to say fishing if someone had just said fish). Another is textual (we should have been more likely to say fishing if there had been a sign on the wall reading FISH); and a third is intraverbal (we should have been more likely to say fishing if we had just read or heard a word that has frequently occurred in proximity with fish). We do not say that fish means or refers to fish when it is an echoic, textual, or intraverbal response. If we tend to say so when it is a tact, it is not because there is a different kind of controlling relation between stimulus and response, but rather because the listener responds in more useful ways with respect to the controlling stimulus.

As the mere probability of responding under the control of a stimulus, a tact evolves as a product of many instances in which a response of a given form has been reinforced in the presence of a given stimulus in many different states of deprivation or aversive stimulation. When tacts are taught as "the names of things," teachers use a generalized reinforcer-such as Good! or some other social reinforcer.

A mand is also a by-product of many instances, in which the controlling variable is a state of deprivation or aversive stimulation. The mand pull evolved when responses having that form were reinforced when listeners pulled different things in different ways upon different occasions. It is possible that mands evolved first, and that they contributed to the evolution of the tact. There are two types of mand. Pull is an action-mand, reinforced when the listener does something. Fish, as short for Give me fish, please is an object-mand, reinforced by the receipt of fish. An object-mand is more likely to occur in the presence of the object because it has more often been reinforced in the presence of that object. We are much more likely to ask for the things we see in a shop because asking for presently available objects has more often been reinforced. (That is one reason why shops exhibit their wares.) The control exerted by the stimulus in an object-mand does not make the response a tact so long as the reinforcing contingencies remain those of a mand-so long as saying fish is reinforced only by the receipt of a fishbut object-mands could have made some contribution to the evolution of a tact of the same form. (It does not follow that a speaker who says fish as a tact will therefore say it as an object-mand, or vice versa [see Skinner, 1957].)

\section{The Evolution of the Autoclitic}

If the occasion upon which a mand or tact has been reinforced recurs essentially unchanged, the behavior needs no further explanation. Reinforcement has had its usual effect. The crucial question is what happens when a person says something he or she has never said before. Novel behavior occurs upon novel occasions, and an occasion is novel in the sense that its features have not appeared together before in the same arrangement. Some features of an occasion strengthen one response, others strengthen another. For example, if two people are walking together and one of them feels a few drops of rain, he may be inclined to say Rain. The present listener or others like him have reacted to that response in reinforcing ways. He or others like him have also reacted in other ways to other features of a setting - when, for example, the speaker has shown surprise or disappointment. On this occasion the speaker may therefore say Rain in a surprised or disappointed tone of voice. Something has been added to the tact. It has been added to other responses in the past with reinforcing consequences but never before to Rain. The possibility of recombining the elements of vocal responses in this way accounts for much of the power and scope of verbal behavior.

Rather more important collateral effects on the listener bring us to the evolution of the autoclitic or, in the traditional term, grammar. An important consideration for the listener is the extent to which he can react to a tact-response effectively. The speaker can help by indicating the nature and strength of the stimulus control of his behavior. If he has felt only a few drops of rain, he can speak in the tone of voice transcribed with a question mark: Rain? The listener is not to respond to the tact without reservation. Other elaborations of the response are needed if the listener is either to respond as he would respond to rain itself or not to respond at all.

Responses that have such effects are Yes and No. They often appear as mands having the effect of Continue and Stop, respectively. Thus, we urge on a speaker who has paused 
by saying Yes? or stop him by saying No! Hearing Rain? Yes!, a listener is more likely to act as if he had felt rain himself. Hearing Rain? No!, he is less likely to do so. In traditional terms, the speaker asserts or denies the presence of rain.

A commoner alternative would be It is raining or It is not raining. Rain? Yes and Rain? No do not have quite the same effect because they suggest questions and answers, but something of the thrust of Yes and No remains. The effect of $Y e s$ can be procured by emphasizing the word is. The speaker is saying, You can safely act upon my response Rain. On the other hand, as a response that brings something the listener is doing to an end (as in saying No to someone about to go the wrong way), No is obviously close to not. It is not raining has the effect of "There are reasons why I tend to say Rain, but do not act upon my response."

The steps through which particular autoclitics may have evolved are usually more obscure than with mands and tacts. An early effort by John Horne Tooke in the Diversions of Purley (1786) has not been fully appreciated. That Tooke was not always right as an etymologist was not as important as his efforts to explain how English speakers could have come to say such words as if, but, or and. "We shall go tomorrow given it does not rain" is a clue to the origin of if. That the boy who stood on the burning deck should be left out in responding to "Whence all (be out he) had fled" is a clue to but. (That Mrs. Hemans wrote all but he instead of all but him is unfortunate but irrelevant.) And when we say and we are often simply adding:

$$
\begin{gathered}
\text { Of shoes-add ships-add sealing wax- } \\
\text { Of cabbages - add kings }
\end{gathered}
$$

As we should put it today, autoclitics have evolved as instructions to the listener that help him behave in ways more likely to have reinforcing consequences and hence more likely to promote reciprocally reinforcing consequences for the speaker.

\section{The Evolution of Sentences}

It is easy to understand the primitive view that behavior is inside the organism before it comes out. Perhaps there is a touch of the primitive in saying that behavior is "emitted," but, as I have pointed out elsewhere, we speak of the emission of light from a hot filament although the light is not in the filament. The reinforcement that strengthens a response does not put the response into the organism; it simply changes the organism so that it is more likely to respond in that way. The point can be made by distinguishing between an operant as a probability of responding and a response as an instance. It is the operant that is "in" the organism, but only in the sense in which elasticity is "in" a rubber band.

What is reinforced in the sense of being followed by a given type of consequences is a response; it is the operant that is reinforced in the quite different sense of being strengthened. Ferster and I made that distinction in the glossary of Schedules of Reinforcement (Ferster \& Skinner, 1957). In the field of verbal behavior it is close to the distinction between the sense of what is said and the saying. The sense of a tact is the controlling variable-traditionally, what it means. The saying is an instance on a given occasion. It is usually not enough to define "what is said" by describing its topography, as in the mand, "Say "haRASS, not HArass." A definition must include a reference to controlling variables, as in "What do you say to that?"

In traditional terms the distinction is close to that between "word" and "sentence." "Sentence" comes from the Latin sentire, meaning "to feel, or think." We ask for a sentence when we say, "How do you feel about that?" or "What do you think of that?" (A dictionary definition of a sentence is "a series of words that expresses a thought." That is an allusion, of course, to another kind of storage. We are said to possess thoughts and bring them out or "express" them by putting them into words.) As I have argued in Verbal Behavior (1957), thinking can be adequately formulated simply as behaving. A sentence is not the expression of a thought; it is the thought. When we say, "It occurred to me to look in my desk," we mean that the behavior of looking in the desk was strengthened, even if it was not executed. When we say, "The thought occurred to me that he was embarrassed," we mean that the verbal behavior $\mathrm{He}$ is embarrassed occurred to us, perhaps covertly. Looking in the desk is behavior; saying " $\mathrm{He}$ is embarrassed" is behavior. We are especially likely to call them thoughts when they are not overtly executed.

\section{THE EVOLUTION OF FACTS}

When we speak of the evolution of the automobile, we do not mean anything like the 
evolution of the horse. We mean the evolution of certain cultural practices through which new ways of making automobiles, as variations, were selected by their contributions to a reinforcing product of human behavior. Some products of verbal behavior may be treated in the same way. Facts, for example.

A fact is a statement about the world. When we say, "The fact of the matter is, I did not attend the meeting," we put the listener in the position of one who attended the meeting and observed that the speaker was not there. One who has been told "the facts of life" acts effectively with respect to certain aspects of daily existence without passing through a series of instructional contingencies. Facts about what has happened in the past (the facts of history) can be helpful in this sense only to the extent that the conditions described are likely to recur. The facts of science are more helpful than those of history because the relevant conditions are more of ten repeated.

We may speak, then, of the evolution of facts - the facts of daily life, of history, or of science. They are often called knowledge. At issue is not the evolution of knowing or of knowledgeable persons, or of any organ of such a person, or of any condition of such an organ, but rather of a verbal environment or culture. People come into contact with such an environment when they listen to speakers or read books. The sounds they hear and the marks they see affect them as listeners or readers, just as the behavior of the original speakers or writers affected their listeners or readers.

We are said to know a fact either because we have already dealt with the contingencies or because we have been "told the fact." Thus, we say, "He must have known the door was unlocked; he would have tried it himself or someone would have told him." But there is another sense in which we may "know" a fact simply as verbal behavior, whether or not it is acted upon. The behavior is intraverbal. The facts of history are examples.

There is an important difference between the intraverbals that result from contiguous usage (the house-home kind of thing) and the larger intraverbals that are learned as such (memorized historical facts or poetry, for example). By reciting facts as strings of intraverbal responses, we advise or inform ourselves, as the original speakers or writers addressed or informed their listeners or readers.

\section{COMMENTS}

It is inevitable that a continuous process like evolution should raise the question of boundaries. Systems for the classification of species are attempts to solve one problem of that kind. At what point can we say that man first appeared on earth? It may be useful to choose a given point to improve our use of the term homo sapiens, but there was presumably no point at which an essence of man came into existence. Similarly, it is only for the sake of consistency that we should try to say when behavior first became verbal. Taking the fishing episode as an example, we could say that $B$ 's response became verbal (1) when it was first strengthened by $A$ 's action in pulling the net (when it became a vocal operant), (2) when the same response was made in other settings with other consequences and came under the exclusive control of a fish as a discriminative stimulus, regardless of any particular state of deprivation or aversive stimulation (when it emerged as a tact), or (3) when it was shaped and maintained by a verbal environment transmitted from one generation to another (when it became part of a "language"). These are all distinguishable steps in the evolution of verbal behavior, and if we are to choose one of them, the most useful appears to be (3). Verbal behavior is behavior that is reinforced through the mediation of other people, but only when the other people are behaving in ways that have been shaped and maintained by a verbal environment or language. At level 3 we could say that other primates have engaged in verbal behavior in artificial verbal environments created by scientists but have not developed a language of their own.

\section{Laughing and Crying}

Two other functions of the vocal musculature-laughing and crying - are, if not exclusively human, at least highly characteristic of the species. There is a good chance that they evolved at about the same time as vocal behavior, but they are not operants, although they can be simulated as such-as in crying to get attention, for example, or laughing politely at an unfunny joke. As phylogenic behavior, they are elicited by positive and negative reinforcers, respectively, often when sudden, but if there is any immediate consequence for those who cry and laugh, it is obscure. Laughing and crying may have evolved because of their effects on others. 
There are those in whom signs of inflicted damage shape and maintain aggression, either nonverbal (a blow) or verbal (an insult) and there are also those in whom signs of relief from damage shape helping others. Other species care for their young and for each other, but presumably not to any great extent as operant behavior. The human species may have gained important advantages when cessation of crying began to reinforce the behavior we call caring.

Laughing, on the other hand, quite obviously reinforces making people laugh and is associated with caring, for in general people laugh when things go well. Just as a courtship dance may have evolved because of its effects on other members of a species rather than upon the dancer, so laughing and crying may have evolved because of their effects on others rather than directly on those who laugh and cry.

\section{Topography}

Theorists of the origin of language have often tried to explain form. Onomatopoeia, for example, has been said to explain why a dog is called a "bow-wow" and why bacon "hisses" or "sizzles" in the frying pan. The gesture for "stop" is a kind of onomatopoeia, and Sir Richard Paget proposed that gesturing with the tongue may have modified the forms of uttered sounds in a useful way (Paget, 1930). Onomatopoeia does not take us very far, and it may not be worthwhile to go further. Forms of words can be traced historically, but seldom back to their origins, and the languages of the world are so diverse that the sources must have been largely adventitious. Children invent new forms readily, and when two or more are living in relative isolation, they may develop fairly extensive idiosyncratic vocabularies. There is probably a reason for the form of every word, as there is probably a reason for the color of every bird or flower, but neither may be worth searching for as a particular fact.

When people began to describe the contingencies of reinforcement in the world around them, words could have been invented as the names of things. The sentence That is called $a$ rose describes a contingency of reinforcement in a verbal environment. Call that a rose is advice to be followed if one is to behave successfully in such an environment. Children soon learn to ask for the names of things, as they ask for tools needed to do things, and it must have been a short step to the invention of a name (Let's call that a rose). The step is taken whenever parents name a child, although very often the form chosen has obvious sources.

\section{CONCLUSION}

To repeat a necessary caveat, I have not tried to say how a verbal environment, or the verbal behavior generated by such an environment, actually evolved. I have merely tried to say how it could have evolved, given the behavioral processes that must already have been exhibited by the species. The paper is speculative, but the speculation is under the restraint imposed by a commitment to the established principles of an operant analysis. In that respect it may be contrasted with the current approaches of linguists. A recent book on essentially the present subject lists a number of explanatory principles or entities, among them "innate language organs," "mechanisms of speech perception," "grammatical competences," "cognitive neural substrates," and the "decoding and production functions of spoken language." It is doubtful whether any of these can be adequately defined without appealing to the observations they are said to explain, and they do not readily account for verbal behavior as such.

\section{REFERENCES}

Ferster, C. B., \& Skinner, B. F. (1957). Schedules of reinforcement. New York: Appleton-Century-Crofts.

Paget, R. A. S. (1930). Human speech. New York: Harcourt, Brace.

Skinner, B. F. (1957). Verbal behavior. New York: Appleton-Century-Crofts.

Skinner, B. F. (1984). The evolution of behavior. Journal of the Experimental Analysis of Behavior, 41, 217222.

Tooke, J. H. (1786). The diversions of Purley. London: J. Johnson.

Received July 8, 1985

Final acceptance September 28, 1985 